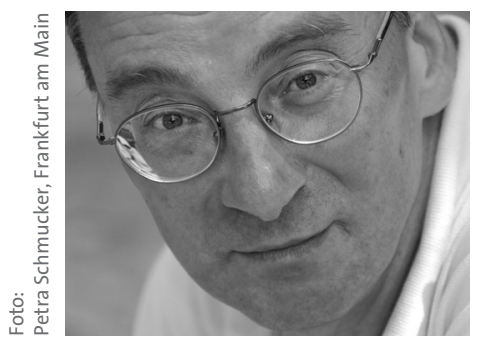

\title{
Das Lobbying professionalisieren
}

Seit der Änderung des Sozialhilfegesetzes zur sachlichen Zuständigkeit ( $\int 97$ SGB XII) vor vier Jahren haben bisher fünf Bundesländer vom Landesrecht Gebrauch gemacht und die Kommunalisierung der Leistungen der Eingliederungshilfe umgesetzt: Thüringen, Brandenburg, Baden-Württemberg, Mecklenburg-Vorpommern und Schleswig-Holstein. Weitere Länder planen die Verlagerung der Verantwortung der Eingliederungshilfe auf die kommunale Ebene oder befinden sich in der modellhaften Erprobung mit ausgewählten Kommunen. Die Eingliederungshilfe ist im sozialen Bereich das bekannteste Beispiel für die Kommunalisierung, also die Verlagerung von Zuständigkeiten vom Bund oder vom Land auf Städte, Gemeinden und Landkreise. Die Beiträge in diesem Heft skizzieren Pro und Kontra dieser Entwicklung. Heben die Befürworter der Kommunalisierung die Verantwortung vor Ort hervor, bangen die Gegner um erreichte Standards und weisen auf die Gefahr des weiteren Auseinanderdriftens der Lebensverhältnisse hin. Doch welche Argumente auch immer man bevorzugt, die Verantwortlichen sozialwirtschaftlicher Organisationen weist Günter Rieger in seinem Beitrag in diesem Heft darauf hin, dass Lobbying das Gebot der Stunde ist. Im neuen Spannungsfeld zwischen Markt, Politik und Zivilgesellschaft müssten sich soziale Akteure heute orientieren, wenn sie erfolgreich Politik machen wollten. Die Pluralisierung der Interessen, Konkurrenz der Anbieter, gesteigerte Komplexität und Interdependenz gesellschaftlicher Handlungsfelder sowie eine zunehmend kritische Öffentlichkeit veränderten die Chancen von Interessenvermittlung und Einflussnahme: Sie zwingen zur Professionalisierung.

Die Vorbereitungen für den nächsten Kongress der Sozialwirtschaft laufen. Am 26. und 27. Mai 2011 wird es in Magdeburg darum gehen, wie sich angesichts von Finanz- und Wirtschaftskrise und der Geldnot der öffentlichen Haushalte die Träger sozialer Dienste und Einrichtungen positionieren können. Unter dem Generalthema »Den Wandel steuern « werden in Vorträgen, Foren und Gruppengesprächen vor allem die beiden Erfolgsfaktoren Personal und Finanzen in den Blick genommen. Aktuelle Informationen zum Stand des Kongresses finden sich auf einer eigenen, neu gestalteten Website: www.kongress-der-sozialwirtschaft.de.

Gerhard Pfannendörfer, Chefredaktion 